\title{
Associations of community, family and early individual factors with body mass index trajectories among children aged 1-18囚a longitudinal study in China
}

\author{
Jing Liang \\ Wuhan University \\ Si Zheng \\ Wuhan University
}

Peigang Wang ( $\square$ wpg926@whu.edu.cn )

Wuhan University

\section{Research Article}

Keywords: BMI, trajectory, children, China

Posted Date: January 18th, 2021

DOl: https://doi.org/10.21203/rs.3.rs-145620/v1

License: (9) This work is licensed under a Creative Commons Attribution 4.0 International License. Read Full License

Version of Record: A version of this preprint was published at Scientific Reports on July 15th, 2021. See the published version at https://doi.org/10.1038/s41598-021-93949-4. 


\section{Abstract}

Recently born children are increasing in height and weight, but no studies have analyzed changes in BMI trajectories and the heterogeneity in China. We aimed to examine the developmental trajectories of BMI among Chinese children and the potential determinants including early individual factors, family and community factors. Data came from the China Family Panel Studies (CFPS 2010, 2012, 2014, 2016, and 2018), and group-based trajectory modeling (GBTM) was employed to identify BMI trajectories from 1 to 18 years. Multivariate logistic regression was conducted to determine the association between early individual, family, community factors and child BMI trajectory. We identified three distinct BMI trajectories among boys and girls: low-increasing, medium-increasing, and high-increasing, and found that early individual factors, family and community factors were associated with different trajectories of BMI. There were heterogeneous BMI trajectories from children to adolescents in the recent Chinese birth cohort. Targeted interventions at early individual, family, community levels are essential.

\section{Introduction}

The prevalence of childhood overweight and obesity is increasing, especially in developing countries ${ }^{1}$. According to the latest Chinese survey report, the prevalence of overweight and obesity was 19\% among children aged $6-17$ and $10.4 \%$ among children under $6^{2}$. It is estimated that by 2030 , the direct economic cost of obesity-related chronic diseases will increase to 49.05 billion RMB per year ${ }^{3}$. Identifying the developmental characteristics of body mass index (BMI) among children of the recent birth cohort and taking effective measures can promote the sustainable development of the society and economy.

The BMI trajectories over age and time of children are highly variable across countries ${ }^{4}$. Most western children began at a moderate level and experienced a relatively rapid BMI increase ${ }^{5}$. A recent longitudinal study also found that BMI developmental trajectories in China are not consistent with those typically found in Western societies ${ }^{6}$. Most Chinese children began at a low level and maintained a small BMI increase across childhood ${ }^{7}$. Characterizing body mass index (BMI) trajectories can investigate obesity development over time and determine the risk factors associated with abnormal growth during childhood ${ }^{5,8}$.

The development of obesity may start early in life, and it is affected by prenatal, perinatal, and postnatal environmental factors ${ }^{9-}$

11. Previous research has established that preterm infants are also at a higher risk of developing childhood obesity than term infants, with low birth weight often accompanied by rapid postnatal weight gain ${ }^{12}$. There is growing evidence that breastfeeding protects against subsequent obesity ${ }^{13,14}$. However, the causes of childhood obesity are multifactorial and complex. Numerous studies indicate that childhood obesity has a significant association with specific family characteristics, the prevalence of child obesity is highest in single-parent families, in lower-income households, and with less educated mothers ${ }^{15-17}$.

With the emergence of social ecological theory, neighborhoods quickly became aspects of interest for obesity both theoretical and practical ${ }^{18-20}$. Results from several epidemiologic studies suggest that modifying residential environments may improve population health and reduce health disparities by increasing health behaviors and minimizing unhealthy exposures ${ }^{21-24}$. The growing BMI of Chinese children is believed to be intertwined with the growth of its market economy ${ }^{25}$. To date in China, there are no comprehensive researches on socio-ecological determinants of BMI among recent cohort children, especially in combination with the growth trajectory and social ecological model.

Therefore, we draw on data from a new longitudinal survey in China to examine the developmental trajectories of BMI among children and the potential determinants including early individual factors, family and community factors. We want to propose a more comprehensive and targeted intervention strategy.

\section{Results}

BMI trajectories. The number of groups and the shapes of BMI trajectories were estimated from 2114 boys and 1762 girls, respectively. Starting from a 1-class model to a 6-class model, a 5-class model yielded an even lower BIC. However, considering cluster size, the average posterior probabilities for each subgroup and OCC, the 3-class model with quadratic and cubic orders was selected as the best fitting model for boys and girls, respectively (Appendix S1- Fit statistics for the trajectory groups 
estimated in the CFPS). Figures 1 and 2 show the three trajectories using data from the CFPS of boys and girls, respectively. Based on the relative position on the BMI scale, trajectories were labeled low-increasing (Class 1, 66.83\% boys, $79.40 \%$ girls), medium-increasing (Class 2, $26.21 \%$ boys, $11.78 \%$ girls), and high-increasing (Class $3,6.94 \%$ boys, $8.82 \%$ girls). Note that there were different trajectories among boys and girls in the Class 2: medium-increasing BMI from early childhood to school period among boys, while high-increasing BMI during early childhood and decreasing BMI during school period among girls. Class 3 had a stable pattern with overweight during puberty, especially among boys. Table 1 summarizes the baseline characteristics of the trajectory groups. 
Table 1

Baseline characteristics of the population-based sample and analysis sample

\begin{tabular}{|c|c|c|c|c|c|c|c|c|}
\hline Variables & Boy & & & & Girls & & & \\
\hline & $\begin{array}{l}\text { Low- } \\
\text { increasing }\end{array}$ & $\begin{array}{l}\text { Medium- } \\
\text { increasing }\end{array}$ & $\begin{array}{l}\text { High- } \\
\text { increasing }\end{array}$ & missing & $\begin{array}{l}\text { Low- } \\
\text { increasing }\end{array}$ & $\begin{array}{l}\text { Medium- } \\
\text { increasing }\end{array}$ & $\begin{array}{l}\text { High- } \\
\text { increasing }\end{array}$ & missing \\
\hline \multicolumn{9}{|c|}{ Early-life factors } \\
\hline Birth weight & & & & 216 & & & & 193 \\
\hline Macrosomia & 167(12.51) & $75(16.74)$ & $17(14.78)$ & & $87(6.69)$ & $20(13.25)$ & $11(9.40)$ & \\
\hline Normal & 1097(82.17) & $352(78.57)$ & $93(80.87)$ & & 1129(86.78) & $120(79.47)$ & $100(85.47)$ & \\
\hline $\begin{array}{l}\text { Low birth } \\
\text { weight }\end{array}$ & $71(5.32)$ & $21(4.69)$ & $5(4.35)$ & & $85(6.53)$ & $11(7.28)$ & $6(5.13)$ & \\
\hline Preterm birth & & & & 20 & & & & 19 \\
\hline Yes & $62(4.25)$ & $20(3.91)$ & $8(6.50)$ & & $59(4.11)$ & $10(5.49)$ & $9(7.09)$ & \\
\hline No & 1397(95.75) & 492(96.09) & 115(93.50) & & 1375(95.89) & 172(94.51) & 118(92.91) & \\
\hline \multicolumn{9}{|c|}{ Breastfeeding duration } \\
\hline$<6$ months & $331(22.49)$ & $94(18.15)$ & $17(13.71)$ & & $324(22.38)$ & $36(19.57)$ & $22(16.92)$ & \\
\hline$>=6$ months & 1141(77.51) & $424(81.85)$ & 107(86.29) & & 1124(77.62) & $148(80.43)$ & 108(83.08) & \\
\hline \multicolumn{9}{|c|}{ Family variables } \\
\hline Family income & & & & 315 & & & & \\
\hline Q1(low) & $297(25.38)$ & $78(24.61)$ & $17(14.66)$ & & $280(25.55)$ & 16(18.39) & $43(36.75)$ & \\
\hline Q2 & $283(24.19)$ & $97(30.60)$ & $30(25.86)$ & & $271(24.73)$ & $28(32.18)$ & $40(34.19)$ & \\
\hline Q3 & $309(26.41)$ & $62(19.56)$ & $40(34.48)$ & & $267(24.36)$ & $21(24.14)$ & $20(17.09)$ & \\
\hline Q4(high) & $281(24.02)$ & $80(25.24)$ & $29(25.00)$ & & $278(25.36)$ & $22(25.29)$ & 14(11.97) & \\
\hline \multicolumn{4}{|c|}{ Mother's education } & 475 & & & & \\
\hline $\begin{array}{l}\text { Primary and } \\
\text { below }\end{array}$ & $532(46.67)$ & $214(53.50)$ & $48(48.48)$ & & $493(43.13)$ & $98(76.56)$ & $45(43.27)$ & \\
\hline $\begin{array}{l}\text { Junior/Senior } \\
\text { High school }\end{array}$ & $514(45.09)$ & 159(39.75) & $44(44.44)$ & & $552(48.29)$ & $30(23.44)$ & $48(46.15)$ & \\
\hline $\begin{array}{l}\text { Junior } \\
\text { College and } \\
\text { above }\end{array}$ & $94(8.25)$ & $27(6.75)$ & $7(7.07)$ & & $98(8.57)$ & $0(0.00)$ & $11(10.58)$ & \\
\hline \multicolumn{9}{|c|}{ Living with parents } \\
\hline Yes & $878(59.65)$ & $312(60.23)$ & $90(72.58)$ & & $864(59.67)$ & 103(55.98) & $79(60.77)$ & \\
\hline No & $594(40.35)$ & 206(39.77) & $34(27.42)$ & & $584(40.33)$ & $81(44.02)$ & $51(39.23)$ & \\
\hline \multicolumn{9}{|l|}{ Single child } \\
\hline Yes & $777(52.79)$ & $283(54.63)$ & $75(60.48)$ & & $780(53.58)$ & $89(48.37)$ & $69(53.08)$ & \\
\hline No & $695(47.21)$ & $235(45.37)$ & 49(39.52) & & $668(46.42)$ & $95(51.63)$ & $61(46.92)$ & \\
\hline
\end{tabular}




\begin{tabular}{|c|c|c|c|c|c|c|}
\hline Variables & Boy & & & Girls & & \\
\hline \multicolumn{7}{|l|}{$\begin{array}{l}\text { Living } \\
\text { location }\end{array}$} \\
\hline Urban & $521(35.39)$ & $356(31.27)$ & $51(41.13)$ & $543(37.50)$ & $40(21.74)$ & $46(35.38)$ \\
\hline Rural & $951(64.61)$ & 162(68.73) & $73(58.87)$ & $905(62.50)$ & $144(78.26)$ & $84(64.62)$ \\
\hline \multicolumn{7}{|c|}{ Community context index } \\
\hline Q1(low) & $360(24.46)$ & $155(29.92)$ & $24(19.35)$ & $358(24.72)$ & $74(40.22)$ & $32(24.62)$ \\
\hline Q2 & $362(24.59)$ & $129(24.90)$ & $33(26.61)$ & $350(24.17)$ & $37(20.11)$ & $39(30.00)$ \\
\hline Q3 & $371(25.20)$ & 118(22.78) & $34(27.42)$ & $369(25.48)$ & $37(20.11)$ & $30(23.08)$ \\
\hline Q4(high) & $379(25.75)$ & 116(22.39) & $33(26.61)$ & $371(25.62)$ & $36(25.96)$ & $29(22.31)$ \\
\hline \multicolumn{7}{|c|}{ Social integration } \\
\hline Actively & $542(36.82)$ & 181(34.94) & $52(41.94)$ & $517(35.70)$ & $55(29.89)$ & $45(34.62)$ \\
\hline Rarely & $631(42.87)$ & $208(40.15)$ & $50(40.32)$ & $626(43.23)$ & $78(42.39)$ & $64(49.23)$ \\
\hline None & $299(20.31)$ & $\begin{array}{l}129 \\
(24.90)\end{array}$ & $22(17.74)$ & $305(21.06)$ & $51(27.72)$ & $21(16.15)$ \\
\hline
\end{tabular}

Association between BMI trajectories and early individual, family and community factors among boys. Table 2 summarizes the results from the multinomial regression examining characteristics associated with trajectory membership among boys. Controlling for multivariate, boys having shorter breastfeeding duration ( $<6$ months) (OR:0.533; 95\% Cl:0.310-0.915) and living with parents (OR:0.469; 95\% Cl:0.302-0.728) were less likely to belong in the high-increasing trajectory than the low-increasing trajectory. But the single child (OR:1.917; 95\% Cl:1.259-2.919) was risk factor for belonging in the high-increasing trajectory. Boys with macrosomia (OR: 1.409; 95\%Cl:1.064-1.867) and none community social cohesion (OR: 1.331; 95\%Cl:1.024-1.731) were more likely to belong on the medium-increasing trajectory than low-increasing trajectory.

Association between BMI trajectories and early individual, family and community factors among girls. Table 3 summarizes the results from the multinomial regression examining characteristics associated with trajectory membership among girls.Macrosomia (OR: 1.768; 95\% Cl:1.081-2.890) was more likely to belong on the medium-increasing than the low-increasing trajectory. In contrast, urban-living (OR:0.658; $95 \% \mathrm{Cl}: 0.439-0.988)$, having a mother with junior/senior high school education (OR:0.450; 95\% Cl:0.310-0.659),living with high family income (Q3, OR:0.490; 95\%Cl:0.302-0.795) and in more advantaged communities (Q2, OR:0.612; 95\%Cl:0.397-0.943; Q3, OR:0.627; 95\%Cl:0.405-0.969) were less likely to belong on the mediumincreasing than the low-increasing trajectory.

\section{Discussion}

This study is the first to investigate the growth trajectories of BMI among children aged 1-18 years in the most recent birth cohort in China. We identified three distinct BMI trajectories among boys and girls from CFPS: low-increasing, medium-increasing, and high-increasing, which is not precisely consistent with the previous studies. The number of trajectories identified and reported ranged from three to seven from the studies of only early childhood or adolescence ${ }^{26}$. Our study focused on the full picture of BMI trajectory throughout childhood and adolescence, which would avoid the transition of the decreasing trajectory from overweight to normal weight ${ }^{27}$.

Moreover, there are sex differences in the BMI trajectories. Especially in the medium-increasing group, medium-increasing BMI from early childhood to school period among boys, while high-increasing BMI during early childhood and decreasing BMI during school period among girls. Girls are more likely to reverse their elevated BMI status in later childhood, consistent with other studies $^{28,29}$. Girls have a greater awareness of weight control than boys ${ }^{30}$, especially when they reached puberty. And consistent 
with previous research ${ }^{31,32}$, overweight is more prevalent among boys in China, and the trajectory of the high-increasing group is similar to that of the developed countries, indicating the differentiation and transformation of children's growth in China.

Besides, we found that early individual factors, family and community factors were associated with different BMI trajectories. Macrosomia was more likely to belong on the medium-increasing trajectory: BMI has been increasing from 1 to 6 years old. Children who had a high birth weight remain at higher odds of overweight or obese in early childhood ${ }^{33-35}$. Boys with a longer breastfeeding duration ( $\geq 6$ months) have high risk of belonging in the high-increasing trajectory in this study. Although several previous studies have suggested that breastfeeding may be associated with a lower BMI in children ${ }^{33,35}$. A nationwide study in China found that children tend to have higher BMI if they received a longer breastfeeding duration ${ }^{36}$. The association of breastfeeding with BMI among Chinese children may be different from developed countries, and more studies are needed to further explore the relationship of breastfeeding with children's BMI in China.

Associations of family variables to BMI trajectories were different for boys and girls ${ }^{16,37}$. Boys single child has a high risk of belonging in the high-increasing trajectory, consistent with the previous studies ${ }^{30,38,39}$. Parenting practice is different for singlechild and multiple-child families. Only-children spend more time on sedentary activities, eating more frequently away from home, more western fast food, and drinking more soft drinks than children with siblings, making them more likely to become obese ${ }^{39-41}$. Girls with higher family socio-economic status were less likely to belong on the medium-increasing trajectory. A previous study suggested that less poor and more educated households are more readily taking advantage of environmental interventions to reduce obesity ${ }^{17}$. Better educated parents are more aware of their child's weight status and the importance of physical activity and healthy eating, thus providing more healthy opportunities and modeling healthier behaviors ${ }^{41}$.

For community variables, boys with none social cohesion were more likely to belong on the medium-increasing trajectory, while girls living in more advantaged communities were less likely to belong to the medium-increasing trajectory. The association of neighborhood environment on physical activity was different between boys and girls ${ }^{39}$. Boys are more likely to spend time with peers in another neighborhood or independently explore other areas, while girls may be restricted by their neighborhoods, associated with less activity ${ }^{33,42}$. Urban-living girls were less likely to belong on the medium-increasing trajectory, suggesting that rural girls are more likely to have a rapid increase in BMI before school age. Along with rapid economic development in rural China, more food has been accessible, and caloric intake has been greater than ever before ${ }^{41}$. Lack of professional health information and healthy lifestyle ${ }^{43}$, children in rural areas are at greater risk of obesity and need more attention.

This study has several limitations. First, using parentreported and child-reported weights and heights to estimate BMI trajectories can bias the trajectories. However, small changes in the bias associated with changing the reporter are unlikely to have a large effect on the overall polynomial function of each trajectory ${ }^{27}$. Second, our sample was selected from a nationally representative data set but our analysis bases on the accelerated longitudinal design that each age cohort can be considered a single cohort. However, each age cohort was similar in terms of descriptive statistics, and we suggest they are unlikely to have a major effect on the conclusions. Third, we analyzed the association between the early individual factors, family and community factors and the BMI trajectoriesunder the social ecology theory, but these self-reported independent variables may be errors or bias. In addition, our study did not distinguish between exclusive and partial breastfeeding, and research shows that exclusive and partial breastfeeding vary in terms of childhood weight outcomes ${ }^{44}$. Lastly, we could not adjust for all possible confounders in relation to BMI because of missing data, availability of data, or problems of harmonization between cohorts. It therefore remains possible that unrecognized confounders or those that are underestimated could be contributing to our results.

Despite these limitations, our study identifies three distinct BMI trajectories among children aged 1-18 in the recently birth cohort, and find sex differences in the trajectories, which highlights the importance of considering heterogeneity in BMI trajectories from children to adolescent. Under the conceptual framework of social ecological theory, we find that early individual, family, and community factors are associated with BMI trajectories. These results also suggest that targeted interventions at multiple levels are very necessary.

\section{Methods}


Materials. This study uses data from the China Family Panel Studies (CFPS) from 2010 to 2018, which is an open-access cohort longitudinal survey. 144 counties from 25 provinces and 640 communities were selected in CFPS, using a multi-strata and multistage sampling method. 25 households including adults and children were selected at random from each community to respond to the questionnaire of family and individual levels, and data about the community level were collected. Previous studies show that the characteristics of the CFPS are comparable to those from the national samples.

We focused on the physical growth of children and adolescents aged 1-18 years old, using data from five waves of the CFPS $(2010,2012,2014,2016$, and 2018). The sample analyzed here was composed of children $1-10$ years old $(n=5665)$ in the first wave who were followed up to wave 4 (9-18 years old). Excluded were children who had no body measurement in the baseline (n $=583)$, those with extreme measurements $(n=782)$, and those with fewer than three BMI measurements $(n=424)$, resulting in an analytic sample of 3876 . We linked the children's survey variables to family and community variables.

Dependent variables. BMI was the dependent variable in this study, which often represents the physical growth of children and adolescents. BMI was defined as weight divided by height squared $(\mathrm{kg} / \mathrm{m} 2)$. Height and weight were parent-reported up to 10 years and self-reported afterward.

Early individual factors. Early individual factors included preterm birth, birthweight and breastfeeding duration. Preterm birth was classified into two categories through the question "What is the gestational age of the child?". The answer was coded "Yes" when less than 9 months and the other was code "No". Birthweight was categorized as "macrosomia (birthweight >= $4 \mathrm{~kg}$ )", "normal $(2.5 \mathrm{~kg}<$ birthweight $<4 \mathrm{~kg}$ )" and "low birth weight (birthweight $<2.5 \mathrm{~kg}$ )" through the question " How many kilograms does the child weigh at birth? ". Breastfeeding duration was derived from survey responses. Breastfeeding duration was a categorical variable with two groups: $<6$ months; and $\geq 6$ months.

Family variables. Family variables were derived from the 2010 baseline data, including family income, mother's education, living with parents and the number of children. Family income was divided into four quartiles (Q1 to Q4), with Q1 and Q4 indicating the lowest and the highest incomes, respectively. Mother's education was classified into three categories including primary school or below, junior high school, and senior high school or above. The number of children was categorized as "single child" and "other". Living with parents was treated a dichotomous variable ("Yes" and "No").

Community variables. Community variables included living location, community context index and community social cohesion. Living location included committee in urban areas and village in rural areas. Community context index was a composite measure generated using factor analysis of six questions responded by the investigators, involved economic conditions, cleanliness of the road, the spiritual outlook of the members, the homogeneity of the members, housing density, and the architectural pattern. The factor scores divided into four quartiles (Q1 to Q4), with Q1 and Q4 indicating the lowest and the highest community context index, respectively. Community social cohesion was classified into three categories( many, little and no), through the question "How many times did your family interact with your neighbors in the last month?" responded by the investigators.

Statistical analysis. The analysis for this study carried out in two stages. In the first stage, group-based trajectory modeling (GBTM) was used to identify BMI trajectories from 1 to 18. GBTM can identify distinctive clusters of individual trajectories within the population using maximum likelihood latent-class models in SAS PROC TRAJ. The optimal number of groups and shapes of trajectories were selected for the best fit to the data using a two-stage approach, as assessed by change in the Bayesian Information Criterion (BIC). Usually, a better BIC is a smaller one. In addition, sufficient cluster size ( $\geq 5 \%$ ), the average posterior probabilities ( $\geq 0.7$ ), odds of correct classification (OCC, $\geq 5$ ) were assessed for the goodness of fit (Nagin,2005). Considering that boys and girls grow up differently, we identified BMI trajectories for boys and girls, respectively.

The second stage of the analysis consisted of conducting logistic regression to determine the association between early-life risk factors, family variables, community variables and child BMI trajectory. Three statistical models were tested: in Model 1, we controlled only for early-life risk factors: preterm birth, birthweight and breastfeeding duration. In Model 2, we added family variables: family income, mother education, living with parents and single child. In Model 3, we added community context variables: living location, community context index and community social cohesion. Multiple imputation was used to account for 
missing data in the independent variables. Ten imputation data sets ${ }^{45}$ were estimated using information from the independent variables in the model. All statistical procedures were performed by using the SAS 9.4.

\section{Data Availability}

The original databases of this study are available from the online site: http://www.isss.pku.edu.cn/cfps/sjzx/gksj/index.htm. 
Table 2

Associations of BMI trajectories among boys with early individual factors, family and community variables

\begin{tabular}{|c|c|c|c|c|c|c|}
\hline \multirow[t]{2}{*}{ Variables } & \multicolumn{3}{|l|}{$\begin{array}{l}\text { Medium- } \\
\text { increasing }\end{array}$} & \multicolumn{3}{|l|}{$\begin{array}{l}\text { High- } \\
\text { increasing }\end{array}$} \\
\hline & Model 1 & Model 2 & Model 3 & Model 1 & Model 2 & Model 3 \\
\hline \multicolumn{7}{|l|}{ Early-life factors } \\
\hline \multicolumn{7}{|l|}{ Birth weight } \\
\hline Macrosomia & $\begin{array}{l}1.378(1.043- \\
1.820)^{\star}\end{array}$ & $\begin{array}{l}1.409(1.064- \\
1.867)^{\star}\end{array}$ & $\begin{array}{l}1.416(1.068- \\
1.878)^{\star}\end{array}$ & $\begin{array}{l}1.317(0.794- \\
2.184)\end{array}$ & $\begin{array}{l}1.470(0.880- \\
2.456)\end{array}$ & $\begin{array}{l}1.473(0.881- \\
2.463)\end{array}$ \\
\hline Normal & 1 & 1 & 1 & 1 & 1 & 1 \\
\hline Low birth weight & $\begin{array}{l}0.909(0.555- \\
1.488)\end{array}$ & $\begin{array}{l}0.869(0.529- \\
1.428)\end{array}$ & $\begin{array}{l}0.852(0.517- \\
1.404)\end{array}$ & $\begin{array}{l}0.806(0.326- \\
1.991)\end{array}$ & $\begin{array}{l}0.862(0.343- \\
2.165)\end{array}$ & $\begin{array}{l}0.879(0.348- \\
2.221)\end{array}$ \\
\hline \multicolumn{7}{|l|}{ Preterm birth } \\
\hline Yes & $\begin{array}{l}1.013(0.589- \\
1.744)\end{array}$ & $\begin{array}{l}1.063(0.617- \\
1.833)\end{array}$ & $\begin{array}{l}1.082(0.626- \\
1.869)\end{array}$ & $\begin{array}{l}1.897(0.846- \\
4.257)\end{array}$ & $\begin{array}{l}1.895(0.834- \\
4.306)\end{array}$ & $\begin{array}{l}1.892(0.830- \\
4.314)\end{array}$ \\
\hline No & 1 & 1 & 1 & 1 & 1 & 1 \\
\hline \multicolumn{7}{|l|}{$\begin{array}{l}\text { Breastfeeding } \\
\text { duration }\end{array}$} \\
\hline$<6$ months & $\begin{array}{l}0.767(0.594- \\
0.991)^{\star}\end{array}$ & $\begin{array}{l}0.786(0.605- \\
1.020)\end{array}$ & $\begin{array}{l}0.777(0.598- \\
1.011)\end{array}$ & $\begin{array}{l}0.534(0.314- \\
0.907)^{\star}\end{array}$ & $\begin{array}{l}0.536(0.313- \\
0.918)^{\star}\end{array}$ & $\begin{array}{l}0.533(0.310- \\
0.915)^{\star}\end{array}$ \\
\hline$>=6$ months & 1 & 1 & 1 & & & 1 \\
\hline \multicolumn{7}{|l|}{ Family variables } \\
\hline \multicolumn{7}{|l|}{ Family income } \\
\hline Q1(low) & & 1 & 1 & & 1 & 1 \\
\hline Q2 & & $\begin{array}{l}0.788(0.592- \\
1.050)\end{array}$ & $\begin{array}{l}0.799(0.599- \\
1.065)\end{array}$ & & $\begin{array}{l}0.681(0.392- \\
1.184)\end{array}$ & $\begin{array}{l}0.669(0.383- \\
1.166)\end{array}$ \\
\hline Q3 & & $\begin{array}{l}0.813(0.608- \\
1.086)\end{array}$ & $\begin{array}{l}0.840(0.627- \\
1.125)\end{array}$ & & $\begin{array}{l}1.161(0.698- \\
1.930)\end{array}$ & $\begin{array}{l}1.121(0.671- \\
1.873)\end{array}$ \\
\hline Q4(high) & & $\begin{array}{l}0.801(0.590- \\
1.088)\end{array}$ & $\begin{array}{l}0.851(0.623- \\
1.163)\end{array}$ & & $\begin{array}{l}0.787(0.439- \\
1.411)\end{array}$ & $\begin{array}{l}0.747(0.413- \\
1.349)\end{array}$ \\
\hline \multicolumn{7}{|l|}{$\begin{array}{l}\text { Mother's } \\
\text { education }\end{array}$} \\
\hline $\begin{array}{l}\text { Primary and } \\
\text { below }\end{array}$ & & 1 & 1 & & 1 & 1 \\
\hline $\begin{array}{l}\text { Junior/Senior } \\
\text { High school }\end{array}$ & & $\begin{array}{l}0.821(0.655- \\
1.029)\end{array}$ & $\begin{array}{l}0.863(0.683- \\
1.090)\end{array}$ & & $\begin{array}{l}0.938(0.620- \\
1.419)\end{array}$ & $\begin{array}{l}0.888(0.580- \\
1.361)\end{array}$ \\
\hline $\begin{array}{l}\text { Junior College } \\
\text { and above }\end{array}$ & & $\begin{array}{l}0.815(0.541- \\
1.228)\end{array}$ & $\begin{array}{l}0.861(0.564- \\
1.314)\end{array}$ & & $\begin{array}{l}0.720(0.333- \\
1.557)\end{array}$ & $\begin{array}{l}0.675(0.306- \\
1.489)\end{array}$ \\
\hline \multicolumn{7}{|l|}{$\begin{array}{l}\text { Living with } \\
\text { parents }\end{array}$} \\
\hline Yes & & $\begin{array}{l}0.919(0.737- \\
1.145)\end{array}$ & $\begin{array}{l}0.886(0.706- \\
1.110)\end{array}$ & & $\begin{array}{l}0.465(0.302- \\
0.716)^{\star}\end{array}$ & $\begin{array}{l}0.469(0.302- \\
0.728)^{\star}\end{array}$ \\
\hline
\end{tabular}




\begin{tabular}{|c|c|c|c|c|}
\hline Variables & $\begin{array}{l}\text { Medium- } \\
\text { increasing }\end{array}$ & & $\begin{array}{l}\text { High- } \\
\text { increasing }\end{array}$ & \\
\hline No & 1 & 1 & 1 & 1 \\
\hline \multicolumn{5}{|c|}{ Single child } \\
\hline Yes & $\begin{array}{l}1.243(0.990- \\
1.562)\end{array}$ & $\begin{array}{l}1.244(0.987- \\
1.567)\end{array}$ & $\begin{array}{l}1.912(1.259- \\
2.902)^{\star}\end{array}$ & $\begin{array}{l}1.917(1.259- \\
2.919)^{\star}\end{array}$ \\
\hline No & 1 & 1 & 1 & 1 \\
\hline \multicolumn{5}{|c|}{$\begin{array}{l}\text { Community } \\
\text { variables }\end{array}$} \\
\hline \multicolumn{5}{|c|}{ Living location } \\
\hline Urban & & $\begin{array}{l}0.903(0.711- \\
1.146)\end{array}$ & & $\begin{array}{l}1.156(0.760- \\
1.758)\end{array}$ \\
\hline Rural & & 1 & & 1 \\
\hline \multicolumn{5}{|c|}{$\begin{array}{l}\text { Community } \\
\text { context index }\end{array}$} \\
\hline Q1(low) & & 1 & & 1 \\
\hline Q2 & & $\begin{array}{l}0.863(0.652- \\
1.142)\end{array}$ & & $\begin{array}{l}1.362(0.781- \\
2.376)\end{array}$ \\
\hline Q3 & & $\begin{array}{l}0.769(0.578- \\
1.024)\end{array}$ & & $\begin{array}{l}1.281(0.736- \\
2.230)\end{array}$ \\
\hline Q4(high) & & $\begin{array}{l}0.784(0.580- \\
1.058)\end{array}$ & & $\begin{array}{l}1.250(0.698- \\
2.237)\end{array}$ \\
\hline \multicolumn{5}{|c|}{ Social integration } \\
\hline Actively & & $\begin{array}{l}1.053(0.835- \\
1.329)\end{array}$ & & $\begin{array}{l}1.285(0.852- \\
1.938)\end{array}$ \\
\hline Rarely & & 1 & & 1 \\
\hline None & & $\begin{array}{l}1.331(1.024- \\
1.731) *\end{array}$ & & $\begin{array}{l}0.986(0.581- \\
1.671)\end{array}$ \\
\hline \multicolumn{5}{|c|}{$\begin{array}{l}\text { Note: Model 1: adjusted for early individual factors: preterm birth, birthweight and breastfeeding duration. Model 2: adjusted } \\
\text { for family variables: family income, mother education, living with parents and single child based on Model } 1 \text {. Model } 3 \text { : } \\
\text { adjusted for community context variables: living location, community context index and community social cohesion based on } \\
\text { Model } 2 \text {. * } P<0.05 \text {. }\end{array}$} \\
\hline
\end{tabular}


Table 3

Associations of BMI trajectories among girls with early individual factors, family and community variables

\begin{tabular}{|c|c|c|c|c|c|c|}
\hline \multirow[t]{2}{*}{ Variables } & \multicolumn{3}{|l|}{ Medium-increasing } & \multicolumn{3}{|l|}{$\begin{array}{l}\text { High- } \\
\text { increasing }\end{array}$} \\
\hline & Model 1 & Model 2 & Model 3 & Model 1 & Model 2 & Model 3 \\
\hline \multicolumn{7}{|l|}{$\begin{array}{l}\text { Early-life risk } \\
\text { factors }\end{array}$} \\
\hline \multicolumn{7}{|l|}{ Birth weight } \\
\hline Macrosomia & $1.934(1.2023 .110)^{\star}$ & $\begin{array}{l}1.835(1.128- \\
2.984)^{\star}\end{array}$ & $\begin{array}{l}1.768(1.081- \\
2.890)^{\star}\end{array}$ & $\begin{array}{l}1.168(0.609- \\
2.240)\end{array}$ & $\begin{array}{l}1.176(0.612- \\
2.259)\end{array}$ & $\begin{array}{l}1.206(0.626- \\
2.323)\end{array}$ \\
\hline Normal & 1 & 1 & 1 & 1 & 1 & 1 \\
\hline $\begin{array}{l}\text { Low birth } \\
\text { weight }\end{array}$ & $\begin{array}{l}1.011(0.532- \\
1.918)\end{array}$ & $\begin{array}{l}0.826(0.430- \\
1.586)\end{array}$ & $\begin{array}{l}0.741(0.383- \\
1.434)\end{array}$ & $\begin{array}{l}0.618(0.259- \\
1.475)\end{array}$ & $\begin{array}{l}0.636(0.265- \\
1.526)\end{array}$ & $\begin{array}{l}0.626(0.260- \\
1.506)\end{array}$ \\
\hline \multicolumn{7}{|l|}{ Preterm birth } \\
\hline Yes & $\begin{array}{l}1.408(0.694- \\
2.857)\end{array}$ & $\begin{array}{l}1.498(0.730- \\
3.075)\end{array}$ & $\begin{array}{l}1.571(0.762- \\
3.238)\end{array}$ & $\begin{array}{l}1.974(0.936- \\
4.161)\end{array}$ & $\begin{array}{l}2.011(0.952- \\
4.249)\end{array}$ & $\begin{array}{l}2.055(0.969- \\
4.358)\end{array}$ \\
\hline No & 1 & 1 & 1 & 1 & 1 & 1 \\
\hline \multicolumn{7}{|c|}{ Breastfeeding duration } \\
\hline$<6$ months & $\begin{array}{l}0.845(0.575- \\
1.243)\end{array}$ & $\begin{array}{l}0.967(0.649- \\
1.440)\end{array}$ & $\begin{array}{l}1.006(0.673- \\
1.505)\end{array}$ & $\begin{array}{l}0.709(0.441- \\
1.141)\end{array}$ & $\begin{array}{l}0.700(0.433- \\
1.133)\end{array}$ & $\begin{array}{l}0.707(0.436- \\
1.145)\end{array}$ \\
\hline$>=6$ months & 1 & & 1 & 1 & 1 & 1 \\
\hline \multicolumn{7}{|l|}{$\begin{array}{l}\text { Family } \\
\text { variables }\end{array}$} \\
\hline \multicolumn{7}{|l|}{$\begin{array}{l}\text { Family } \\
\text { income }\end{array}$} \\
\hline Q1(low) & & 1 & 1 & & 1 & 1 \\
\hline Q2 & & $\begin{array}{l}0.721(0.481- \\
1.081)\end{array}$ & $\begin{array}{l}0.764(0.507- \\
1.152)\end{array}$ & & $\begin{array}{l}0.847(0.495- \\
1.448)\end{array}$ & $\begin{array}{l}0.884(0.515- \\
1.516)\end{array}$ \\
\hline Q3 & & $\begin{array}{l}0.433(0.269- \\
0.698)^{\star}\end{array}$ & $\begin{array}{l}0.490(0.302- \\
0.795)^{\star}\end{array}$ & & $\begin{array}{l}1.003(0.598- \\
1.682)\end{array}$ & $\begin{array}{l}1.055(0.624- \\
1.784)\end{array}$ \\
\hline Q4(high) & & $\begin{array}{l}0.659(0.418- \\
1.039)\end{array}$ & $\begin{array}{l}0.737(0.458- \\
1.186)\end{array}$ & & $\begin{array}{l}1.260(0.746- \\
2.128)\end{array}$ & $\begin{array}{l}1.382(0.804- \\
2.376)\end{array}$ \\
\hline \multicolumn{7}{|l|}{$\begin{array}{l}\text { Mother's } \\
\text { education }\end{array}$} \\
\hline $\begin{array}{l}\text { Primary and } \\
\text { below }\end{array}$ & & 1 & 1 & & 1 & 1 \\
\hline $\begin{array}{l}\text { Junior/Senior } \\
\text { High school }\end{array}$ & & $\begin{array}{l}0.401(0.279- \\
0.575)^{\star}\end{array}$ & $\begin{array}{l}0.450(0.310- \\
0.653)^{\star}\end{array}$ & & $\begin{array}{l}1.011(0.668- \\
1.530)\end{array}$ & $\begin{array}{l}1.067(0.698- \\
1.631)\end{array}$ \\
\hline $\begin{array}{l}\text { Junior } \\
\text { College and } \\
\text { above }\end{array}$ & & $\begin{array}{l}0.405(0.198- \\
0.829)^{\star}\end{array}$ & $\begin{array}{l}0.500(0.240- \\
1.041)\end{array}$ & & $\begin{array}{l}0.841(0.401- \\
1.761)\end{array}$ & $\begin{array}{l}0.895(0.420- \\
1.906)\end{array}$ \\
\hline
\end{tabular}

Note: Model 1: adjusted for early individual factors: preterm birth, birthweight and breastfeeding duration. Model 2: adjusted for family variables: family income, mother education, living with parents and single child based on Model 1. Model 3: adjusted for community context variables: living location, community context index and community social cohesion based on Model 2. * $P<0.05$. 


\begin{tabular}{|c|c|c|c|c|}
\hline Variables & Medium-increasing & & $\begin{array}{l}\text { High- } \\
\text { increasing }\end{array}$ & \\
\hline Yes & 1 & 1 & 1 & 1 \\
\hline No & $\begin{array}{l}1.307(0.920- \\
1.856)\end{array}$ & $\begin{array}{l}1.249(0.869- \\
1.795)\end{array}$ & $\begin{array}{l}0.928(0.622- \\
1.385)\end{array}$ & $\begin{array}{l}0.924(0.614- \\
1.392)\end{array}$ \\
\hline \multicolumn{5}{|c|}{ Single child } \\
\hline Yes & $\begin{array}{l}1.090(0.755- \\
1.573)\end{array}$ & $\begin{array}{l}1.106(0.761- \\
1.609)\end{array}$ & $\begin{array}{l}0.982(0.647- \\
1.491)\end{array}$ & $\begin{array}{l}0.985(0.647- \\
1.501)\end{array}$ \\
\hline No & 1 & 1 & 1 & 1 \\
\hline \multicolumn{5}{|c|}{$\begin{array}{l}\text { Community } \\
\text { variables }\end{array}$} \\
\hline \multicolumn{5}{|l|}{$\begin{array}{l}\text { Living } \\
\text { location }\end{array}$} \\
\hline Urban & & $\begin{array}{l}0.658(0.439- \\
0.988)^{\star}\end{array}$ & & $\begin{array}{l}0.915(0.601- \\
1.391)\end{array}$ \\
\hline Rural & & 1 & & 1 \\
\hline \multicolumn{5}{|c|}{ Community context index } \\
\hline Q1(low) & & 1 & & 1 \\
\hline Q2 & & $\begin{array}{l}0.612(0.397- \\
0.943)^{\star}\end{array}$ & & $\begin{array}{l}1.250(0.762- \\
2.051)\end{array}$ \\
\hline Q3 & & $\begin{array}{l}0.627(0.405- \\
0.969)^{\star}\end{array}$ & & $\begin{array}{l}0.904(0.533- \\
1.532)\end{array}$ \\
\hline Q4(high) & & $\begin{array}{l}0.724(0.456- \\
1.150)\end{array}$ & & $\begin{array}{l}0.845(0.488- \\
1.463)\end{array}$ \\
\hline \multicolumn{5}{|l|}{$\begin{array}{l}\text { Social } \\
\text { integration }\end{array}$} \\
\hline Actively & & $\begin{array}{l}0.916(0.629- \\
1.334)\end{array}$ & & $\begin{array}{l}0.853(0.569- \\
1.277)\end{array}$ \\
\hline Rarely & & 1 & & 1 \\
\hline None & & $\begin{array}{l}1.374(0.928- \\
2.033)\end{array}$ & & $\begin{array}{l}0.700(0.418- \\
1.173)\end{array}$ \\
\hline \multicolumn{5}{|c|}{$\begin{array}{l}\text { Note: Model 1: adjusted for early individual factors: preterm birth, birthweight and breastfeeding duration. Model 2: adjusted } \\
\text { for family variables: family income, mother education, living with parents and single child based on Model 1. Model } 3 \text { : } \\
\text { adjusted for community context variables: living location, community context index and community social cohesion based on } \\
\text { Model 2. }{ }^{*} P<0.05 \text {. }\end{array}$} \\
\hline
\end{tabular}

\section{Declarations}

\section{Acknowledgements (not compulsory)}

The data were from China Family Panel Studies (CFPS). We thank the Institute of Social Science Survey of Peking University for the CFPS data collection and analysis files. Thank you to the numerous staff members who have made tremendous efforts and selfless contributions to the CFPS investigation.

\section{Author contributions statement}


Jing Liang and Si Zheng participated in study conception, data analysis, data interpretation, article drafting and approved the final article. Peigang Wang contributed to the study design and critical revision. Jing Liang and Si Zheng contributed equally to this article.

\section{Competing interests}

The authors declare no competing interests.

\section{References}

1 Juonala, M. et al. Childhood adiposity, adult adiposity, and cardiovascular risk factors. N. Engl. J. Med.365, 1876-1885, doi:10.1056/NEJMoa1010112 (2011).

2 China, N. H. C. o. t. P. s. R. o. The Report on the Status of Nutrition and Chronic Diseases of Chinese residents. (People's Medical Publishing House, 2020).

3 Ma, G. S. Report on Childhood Obesity in China. 15 (People's Medical Publishing House, 2017).

4 Collaboration, N. C. D. R. F. Height and body-mass index trajectories of school-aged children and adolescents from 1985 to 2019 in 200 countries and territories: a pooled analysis of 2181 population-based studies with 65 million participants. Lancet396, 15111524, doi:10.1016/S0140-6736(20)31859-6 (2020).

5 Carter, M. A., Dubois, L., Tremblay, M. S., Taljaard, M. \& Jones, B. L. Trajectories of childhood weight gain: the relative importance of local environment versus individual social and early life factors. PLoS One7, e47065, doi:10.1371/journal.pone.0047065 (2012).

6 Liang, Y. \& Qi, Y. Developmental trajectories of adolescent overweight/obesity in China: socio-economic status correlates and health consequences. Public Health185, 246-253, doi:10.1016/j.puhe.2020.05.013 (2020).

7 Fan, H. \& Zhang, X. Body mass index trajectory across childhood and subsequent risk of elevated blood pressure. Journal of Clinical Hypertension22, 1902-1907, doi:10.1111/jch.14001 (2020).

8 Geserick, M. et al. Acceleration of BMI in Early Childhood and Risk of Sustained Obesity. N. Engl. J. Med.379, 1303-1312, doi:10.1056/NEJMoa1803527 (2018).

9 Bernhardsen, G. P. et al. Early life risk factors for childhood obesity-Does physical activity modify the associations? The MoBa cohort study. Scand. J. Med. Sci. Sports29, 1636-1646, doi:10.1111/sms.13504 (2019).

10 Koplin, J. J. et al. Infant and young child feeding interventions targeting overweight and obesity: A narrative review. Obes. Rev.20, 31-44, doi:10.1111/obr.12798 (2019).

11 Wood, C. T. et al. Antecedents of Obesity Among Children Born Extremely Preterm. Pediatrics142, 8, doi:10.1542/peds.20180519 (2018).

$12 \mathrm{Li}, \mathrm{P}$. et al. Nutritional status and risk factors of overweight and obesity for children aged 9-15 years in Chengdu, Southwest China. BMC Public Health12, 636, doi:10.1186/1471-2458-12-636 (2012).

13 Singhal, A. \& Lanigan, J. Breastfeeding, early growth and later obesity. Obes. Rev.8, 51-54, doi:10.1111/j.1467-

789X.2007.00318.x (2007).

14 Wu, Y. Y., Lye, S., Dennis, C. L. \& Briollais, L. Exclusive breastfeeding can attenuate body-mass-index increase among genetically susceptible children: A longitudinal study from the ALSPAC cohort. PLoS Genet.16, 14, doi:10.1371/journal.pgen.1008790 (2020). 
15 Dos Santos, C. S., Picoito, J., Nunes, C. \& Loureiro, I. Early Individual and Family Predictors of Weight Trajectories From Early Childhood to Adolescence: Results From the Millennium Cohort Study. Front Pediatr8, 417, doi:10.3389/fped.2020.00417 (2020).

16 Hankey, M. S. \& Miyazaki, Y. Multilevel analysis of BMI growth trajectories of US school children: Features and risk factors. SSM-Popul. Health8, 12, doi:10.1016/j.ssmph.2019.100455 (2019).

17 Nobari, T. Z., Whaley, S. E., Prelip, M. L., Crespi, C. M. \& Wang, M. C. Trends in Socioeconomic Disparities in Obesity Prevalence among Low-Income Children Aged 2-4 Years in Los Angeles County, 2003-2014. Child Obes.14, 248-258, doi:10.1089/chi.2017.0264 (2018).

18 Black, J. L. \& Macinko, J. Neighborhoods and obesity. Nutr. Rev.66, 2-20, doi:10.1111/j.1753-4887.2007.00001.x (2008).

19 Ludwig, J. et al. Neighborhoods, Obesity, and Diabetes - A Randomized Social Experiment. N. Engl. J. Med.365, 1509-1519, doi:10.1056/NEJMsa1103216 (2011).

20 Rachele, J. N., Kavanagh, A. M., Brown, W. J., Healy, A. M. \& Turrell, G. Neighborhood Disadvantage and Body Mass Index: A Study of Residential Relocation. Am. J. Epidemiol.187, 1696-1703, doi:10.1093/aje/kwx390 (2018).

21 DeWeese, R. S. et al. Patterns of food and physical activity environments related to children's food and activity behaviors: A latent class analysis. Health Place49, 19-29, doi:10.1016/j.healthplace.2017.11.002 (2018).

22 Ding, D. \& Gebel, K. Built environment, physical activity, and obesity: What have we learned from reviewing the literature? Health Place18, 100-105, doi:10.1016/j.healthplace.2011.08.021 (2012).

23 Economos, C. D. et al. Shape Up Somerville two-year results: A community-based environmental change intervention sustains weight reduction in children. Prev. Med.57, 322-327, doi:10.1016/j.ypmed.2013.06.001 (2013).

24 Sallis, J. F., Floyd, M. F., Rodriguez, D. A. \& Saelens, B. E. Role of Built Environments in Physical Activity, Obesity, and Cardiovascular Disease. Circulation125, 729-737, doi:10.1161/circulationaha.110.969022 (2012).

25 Fu, Q. \& George, L. K. Sex, Socioeconomic and Regional Disparities in Age Trajectories of Childhood BMI, Underweight and Overweight in China. Asian Population Studies11, 134-148, doi:10.1080/17441730.2015.1038873 (2015).

26 Mattsson, M. et al. Group-based trajectory modelling for BMI trajectories in childhood: A systematic review. Obes. Rev.20, 9981015, doi:10.1111/obr.12842 (2019).

27 Tu, A. W., Masse, L. C., Lear, S. A., Gotay, C. C. \& Richardson, C. G. Body mass index trajectories from ages 1 to 20: Results from two nationally representative canadian longitudinal cohorts. Obesity23, 1703-1711, doi:10.1002/oby.21158 (2015).

28 Buscot, M. J. et al. Distinct child-to-adult body mass index trajectories are associated with different levels of adult cardiometabolic risk. European Heart Journa/39, 2263-2270, doi:10.1093/eurheartj/ehy161 (2018).

29 Wang, V. H. et al. What factors may contribute to sex differences in childhood obesity prevalence in China? Public Health Nutrition21, 2056-2064, doi:10.1017/S1368980018000290 (2018).

30 Cai, L. et al. One-child policy, weight status, lifestyles and parental concerns in Chinese children: a nationwide cross-sectional survey. European Journal of Clinical Nutrition72, 1150-1158, doi:10.1038/s41430-018-0178-y (2018).

31 Kim, T., Kwon, J., Lee, C. G. \& Jang, C. Y. Longitudinal analysis of Socioecological obesogenic factors in a National Sample of U.S. children. Archives of Public Health78, 116, doi:10.1186/s13690-020-00494-z (2020).

$32 \mathrm{Min}, \mathrm{J} ., \mathrm{Li}, \mathrm{J} ., \mathrm{Li}, \mathrm{Z}$. \& Wang, Y. Impacts of infancy rapid weight gain on 5-year childhood overweight development vary by age and sex in China. Pediatr. Obes.7, 365-373, doi:10.1111/j.2047-6310.2012.00074 (2012). 
33 Danielzik, S., Czerwinski-Mast, M., Langnase, K., Dilba, B. \& Muller, M. J. Parental overweight, socioeconomic status and high birth weight are the major determinants of overweight and obesity in 5-7 y-old children: baseline data of the Kiel Obesity Prevention Study (KOPS). International Journal of Obesity28, 1494-1502, doi:10.1038/sj.ijo.0802756 (2004).

34 Matthews, E. K., Wei, J. \& Cunningham, S. A. Relationship between prenatal growth, postnatal growth and childhood obesity: a review. European Journal of Clinical Nutrition71, 919-930, doi:10.1038/ejcn.2016.258 (2017).

35 Eny, K. M. et al. Breastfeeding duration, maternal body mass index, and birth weight are associated with differences in body mass index growth trajectories in early childhood. American Journal of Clinical Nutrition107, 584-592, doi:10.1093/ajcn/nqx081 (2018).

36 Jing, H. Q. et al. Effect of Breastfeeding on Childhood BMI and Obesity The China Family Panel Studies. Medicine93, doi:10.1097/md.0000000000000055 (2014).

37 Stahlmann, K. et al. A cross-sectional study of obesogenic behaviours and family rules according to family structure in European children. International Journal of Behavioral Nutrition and Physical Activity17, 32, doi:10.1186/s12966-020-00939-2 (2020).

38 Haugaard, L. K., Ajslev, T. A., Zimmermann, E., Angquist, L. \& Sorensen, T. I. A. Being an Only or Last-Born Child Increases Later Risk of Obesity. PLoS One8, doi:10.1371/journal.pone.0056357 (2013).

39 Ochiai, H. et al. Number of siblings, birth order, and childhood overweight: a population-based cross-sectional study in Japan. BMC Public Health12, 766, doi:10.1186/1471-2458-12-766 (2012).

40 Tian, X. \& von Cramon-Taubadel, S. Are only children in China more likely to be obese overweight than their counterparts with siblings? Econ. Hum. Biol.37, 13, doi:10.1016/j.ehb.2020.100847 (2020).

41 Hesketh, K., Crawford, D., Salmon, J., Jackson, M. \& Campbell, K. Associations between family circumstance and weight status of Australian children. International Journal Of Pediatric Obesity2, 86-96, doi:10.1080/17477160601148554 (2007).

42 Roemmich, J. N., Epstein, L. H., Raja, S. \& Yin, L. The neighborhood and home environments: disparate relationships with physical activity and sedentary behaviors in youth. Annals of Behavioral Medicine33, 29-38, doi:10.1207/s15324796abm3301_4 (2007).

43 Gordon-Larsen, P., Wang, H. \& Popkin, B. M. Overweight dynamics in Chinese children and adults. Obes. Rev.15, 37-48, doi:10.1111/obr.12121 (2014).

44 Rzehak, P. et al. Infant feeding and growth trajectory patterns in childhood and body composition in young adulthood. American Journal of Clinical Nutrition106, 568-580, doi:10.3945/ajcn.116.140962 (2017).

45 van Buuren, S. Multiple imputation of discrete and continuous data by fully conditional specification. Statistical Methods in Medical Research16, 219-242, doi:10.1177/0962280206074463 (2007).

\section{Additional Information}

Fig. 1. Three trajectories of BMI among boys aged from 1-18, CFPS

\begin{tabular}{|llllll|}
\hline Group & \multirow{2}{*}{ Group membership } & \multicolumn{4}{l|}{ Growth parameter(standard errors) } \\
\cline { 3 - 6 } & & intercept & slope & quadratic & cubic \\
\hline Class 1 & $66.83 \%$ & $18.838(0.214)$ & $-0.556(0.048)$ & $0.033(0.003)$ & \\
\hline Class 2 & $26.21 \%$ & $17.251(0.917)$ & $-0.073(0.328)$ & $0.069(0.035)$ & $-0.003(0.001)$ \\
\hline Class 3 & $6.94 \%$ & $22.785(1.433)$ & $-2.263(0.550)$ & $0.368(0.062)$ & $-0.013(0.002)$ \\
\hline
\end{tabular}


Fig. 2. Three trajectories of BMI among girls aged from 1-18, CFPS

\begin{tabular}{|llllll|}
\hline Group & \multirow{2}{*}{ Group membership } & \multicolumn{4}{l|}{ Growth parameter(standard errors) } \\
\cline { 3 - 6 } & & intercept & slope & quadratic & cubic \\
\hline Class 1 & $79.40 \%$ & $18.744(0.198)$ & $-0.586(0.044)$ & $0.037(0.002)$ & \\
\hline Class 3 & $11.78 \%$ & $12.134(1.379)$ & $3.814(0.512)$ & $-0.422(0.057)$ & $0.013(0.002)$ \\
\hline Class 2 & $8.82 \%$ & $18.318(1.594)$ & $-0.828(0.600)$ & $0.180(0.066)$ & $-0.006(0.002)$ \\
\hline
\end{tabular}

\section{Figures}

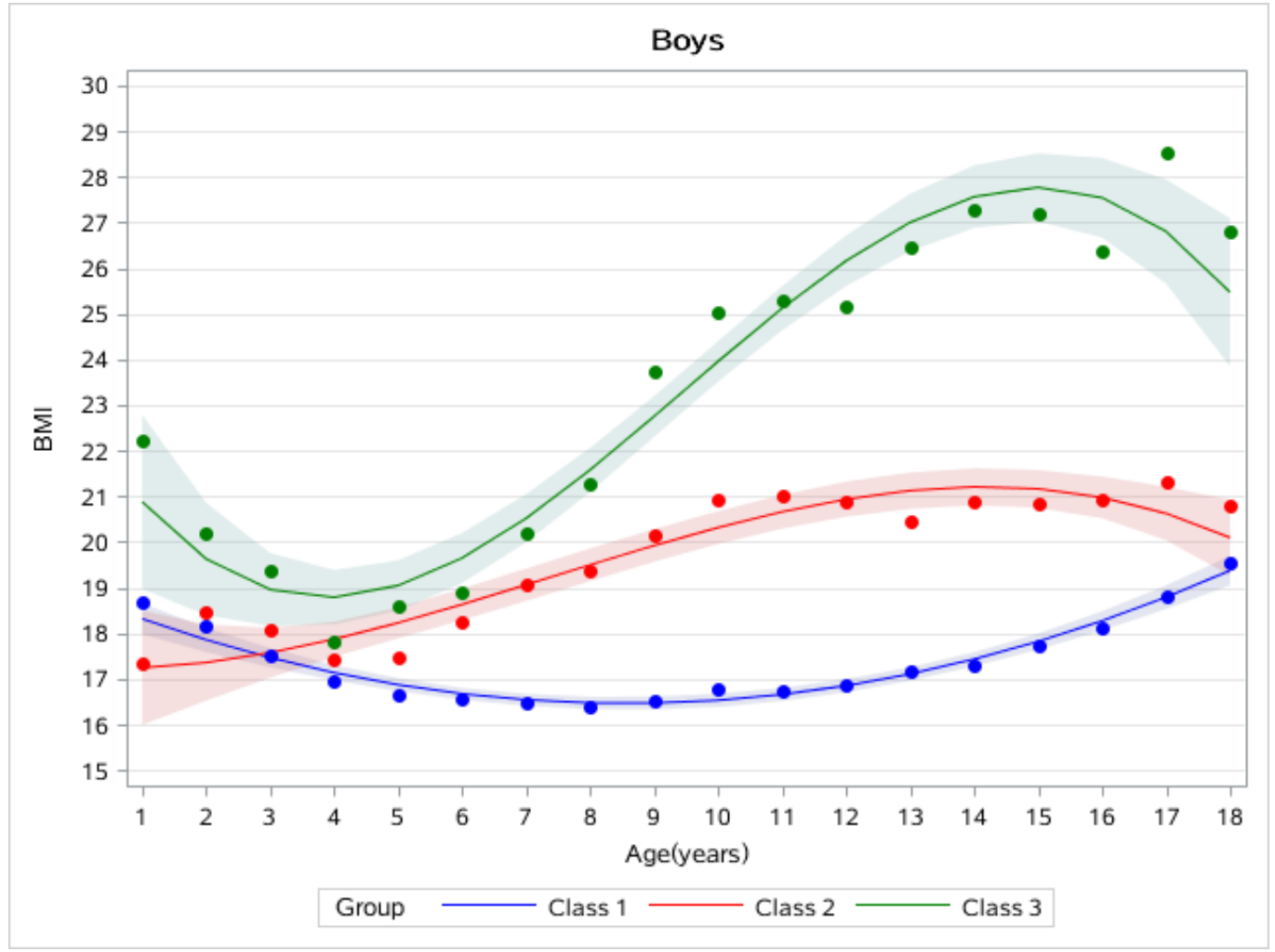

\section{Figure 1}

Three trajectories of BMI among boys aged from 1-18, CFPS 


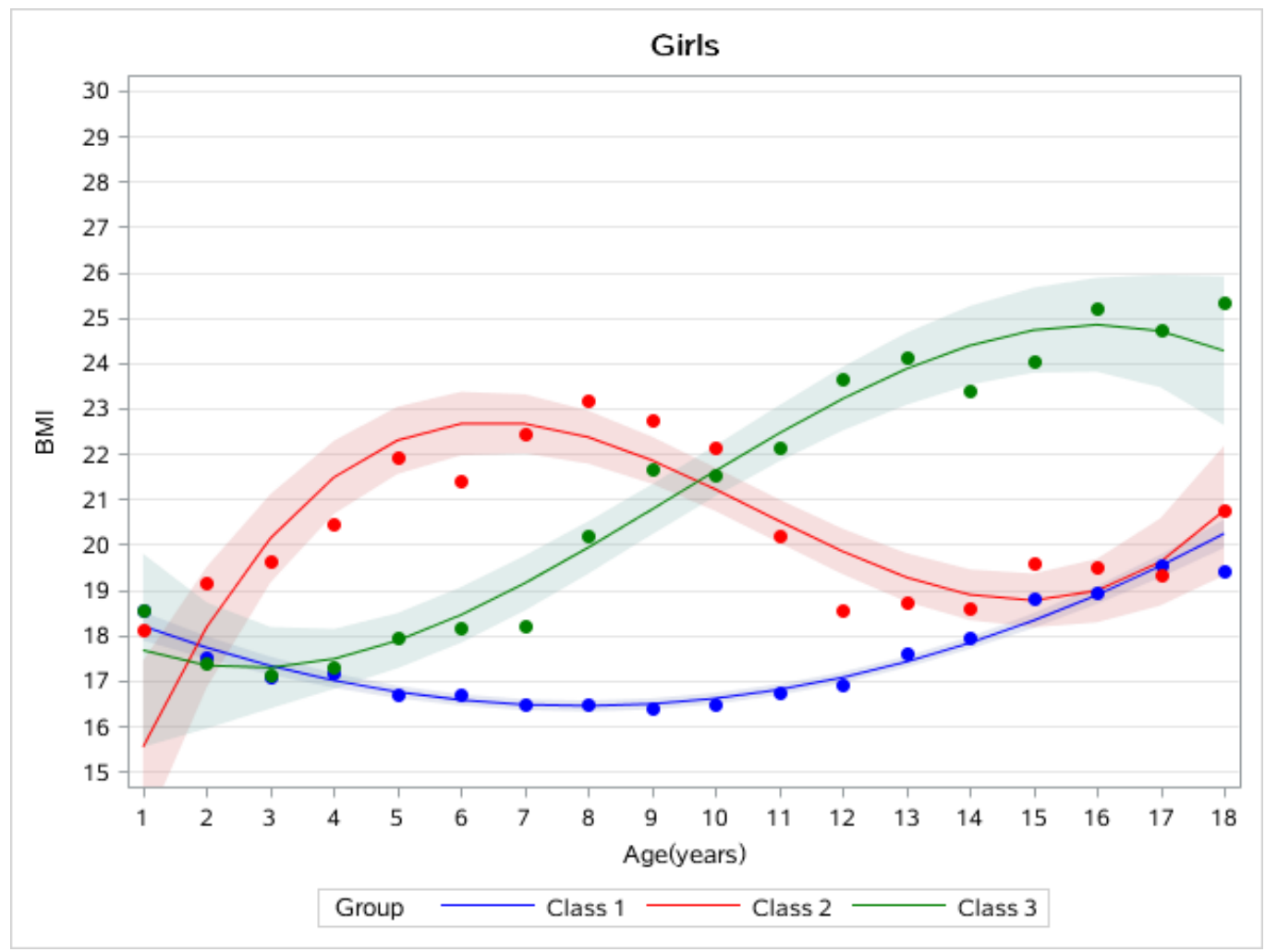

\section{Figure 2}

Three trajectories of BMI among girls aged from 1-18, CFPS

\section{Supplementary Files}

This is a list of supplementary files associated with this preprint. Click to download.

- AppendixS1.docx 